\title{
Reviews in the time of COVID
}

\author{
Jonathan Simon ${ }^{1}$
}

Published online: 14 October 2020

(c) Springer Nature B.V. 2020

At the beginning of this year, I replaced Luciano Boschiero as the history of science editor for Metascience, and I would like to thank him for the hard work he has put into the journal as well as the help he gave me in getting up to speed. Brad Wray and Lori Nash also showed me the ropes, with Palanimathu Athimoolam, Ties Nijssen and Eric Pieren taking care of the publishing side for Springer with great professionalism and efficiency.

As university administrators and managers strive to get more academic value for money out of their staff, academics are under unrelenting pressure to publish. Unfortunately, academic book reviews do not count for a great deal in the evaluation of research, and so some researchers are reluctant to take on the task of writing a book review. This is regrettable, as reviews have the merit of not only helping hard-pressed colleagues to keep abreast of outlying literature associated with their area of expertise but also allowing specialists to engage with published research in a more rigorous way than might otherwise be the case. One positive side effect of the overworked condition of academics is that it gives an opportunity for early-career colleagues to publish as well. In this issue we have a freshly minted $\mathrm{PhD}$ writing on the history of skin lighteners, giving us a taste of how subjects and approaches are evolving with the arrival of these fresh talents.

The symposium around David Miller's new book on James Watt demonstrates what leading academics have to offer in terms of research and reflection with its three thoughtful reviews and a stimulating response. Indeed, the value of book reviews is perhaps most evident when a book is discussed from a variety of perspectives and an author is given a chance to address the critics, as in the case of a symposium. Through these symposia and the other reviews in Metascience, we are looking to sustain a virtuous circle based on the academic community's recognition of quality and timely reviews of books in the delimited and yet now very extensive area of science studies.

As we are all painfully aware, an unpredictable factor has now entered all our lives: COVID-19. The sudden upturn in interest in the logic of clinical trials, the history of the Spanish flu and vaccination, among other subjects, has brought to light

Jonathan Simon

jonathan.simon@univ-lorraine.fr

1 Archives Poincaré UMR 7117, Philosophy Department, University of Lorraine, Nancy, France 
the value of science studies in understanding this exceptional global medico-politico-scientific phenomenon. We can hope that our academic community will benefit in return from the light it has been able to shine on the pandemic, which is maybe not as unprecedented as many seem to think. On the practical side, the epidemic has underlined the importance of the online availability of reviews, although the reaction of several publishers to only provide electronic versions of their books for review has not been to the taste of the majority of our reviewers.

The review of the global history of phrenology in the pages of this issue reminds us that the fashion for 'global history' remains dominated by an Anglo-American perspective concerning what is ultimately of interest in the global. Hopefully, we can contribute to making global history (and philosophy) of science more global. As I live and work in France, you can expect to see more French contributors to the journal, but we will also be recruiting more reviewers from Central and Eastern Europe, Central and South America and Asia. The review of a book on the X-Club encourages us to reflect on the importance of networks in science, and networks are what allow this journal to function. In an effort to strengthen our own network of reviewers, I would like to offer all our collaborators a big thank you and encourage those colleagues interested in reviewing to contact the editors.

Publisher's Note Springer Nature remains neutral with regard to jurisdictional claims in published maps and institutional affiliations. 